\title{
Performance Evaluation and Cost Economics of Developed Manual Paddy Transplanter
}

\author{
Surendra Pal, Ashok Tripathi, Suryakanta Khandai* and Ashish Kumar Kerketta \\ Department of Farm Machinery and Power Engineering, VSAET, SHUATS, Allahabad \\ 211007, India
}

*Corresponding author

\begin{abstract}
A B S T R A C T
Key words

missing hill, No of hill, Field

efficiency, Manual transplanter, Wash root

Article Info

Accepted:

20 November 2018

Available Online:

10 December 2018

Transplanting is most laborious consuming operation during paddy cultivation. The cost of puddling and transplanting share 50 percentage of the total producing cost. The man day required for transplanting ranging from 50-60 man-day/ha and labour are very costly. So newly developed manual paddy transplanter is fit to the requirement for small and marginal farmers due to wash root type seedling can be transplanted in the field. The performance of the transplanter was evaluated. Missing hill is comparatively low while using in the field and row-row distance is maintained by $25 \mathrm{~cm}$. No of hills with no of seedlings per square meter is also maintained properly and it varies between $45-55$ seedlings per square meter. Field efficiency for designed transplanter is $52 \%$ for standing water of $0.6 \mathrm{~cm}$ and $44.4 \%$ for standing water of $0.3 \mathrm{~cm}$.
\end{abstract}

\section{Introduction}

About 90 per cent of rice grown in the world is produced and consumed only in Asian countries. In India rice crop is planted in almost all the states on 43.95 Mha area. The total rice production of India was 106.5 Mt in 2013-14 (Anonymous, 2015).Rice cultivation is a complex activity that requires a series of processes to achieve the finished product. The basic stages of cultivation include: Seed selection, Land preparation and Crop establishment. Lot of effect are made by the scientist to include the mechanical transplanter in the country. Initially the machine work imported from the countries like china japan and Korea. A ten row manually operated machine for root washed seedling known as "Annapurna Paddy transplanter" was developed and evaluated at many paces in India 1973. Transplanting is most laborious consuming operation during paddy cultivation. The cost of puddling and transplanting share 50 percentage of the total producing cost. The man day required for transplanting ranging from 50-60 man-day/ha. 
Now a day labour are very costly and scares. The delay in transplanting directly affect the yield. Hence the transplanting operation needs to mechanized. Transplanting cab be done by manually or by using transplanter, different type of trasplanter are available like manually operated, power tiller operates, riding operated, tractor operated and self-propelled type operator. Uttar Pradesh ranks number second with a total rice production of 140.22 lakh tons.

The performance of machine was not satisfactory because of high missing of hills and more labour requirement (Mahapatra R.1973). a two row self-propelled transplanter was imparted from japan in 1983. This machine has this advantage like low capacity, low pant population of power sources (Singh and Gard, 1984). So the newly developed manual wash root paddy transplanter was tested in field and its performance was evaluated along with its cost economics.

\section{Materials and Methods}

\section{Speed of operation}

The transplanting speed was obtained by recording the time required for the rice transplanter to travel a $20 \mathrm{~m}$ distance in the field. The speed of transplanting was computed using the following equation

$S=\frac{D}{t} \times 3.6$

where,

$\mathrm{S}=$ Transplanting speed, $\mathrm{km} / \mathrm{h}$;

$\mathrm{D}=$ Distance, $\mathrm{m}$; and

$\mathrm{t}=$ Time required to cover the distance $\mathrm{D}$, sec.

\section{Actual field capacity}

It is the tactual area covered per unit time including the time loss in turning, feeding the seedlings on tray, repair and adjustment. It was calculated as

$\mathrm{AFC}=\frac{A}{T t} \quad \ldots(2)$

where,

$\mathrm{AFC}=$ Actual field capacity, ha/h;

$\mathrm{A}=$ Total transplanted area, ha; and

$\mathrm{Tt}=$ Total operating time required for transplanting, $\mathrm{h}$.

\section{Theoretical field capacity}

It is the theoretical area covered per unit time eliminating the time loss in turning, feeding the seedlings on tray, repair and adjustment. It is the function of speed of transplanter and the width of operation expressed in ha/hr and it was calculated by the following equation

$\mathrm{TFC}=\frac{w \times s}{10}$

where,

$\mathrm{TFC}=$ Theoretical field capacity, ha/h;

$\mathrm{W}=$ Operating width of the transplanter, $\mathrm{m}$; and

$\mathrm{S}=$ Transplanting speed, $\mathrm{km} / \mathrm{h}$.

\section{Field efficiency}

It is the ratio of the actual field capacity and theoretical field capacity expressed in percentage. The field efficiency was calculated using following formula.

$\mathrm{FE}=\frac{A F C}{T F C}$

where,

$\mathrm{FE}=$ Field efficiency, \%;

$\mathrm{AFC}=$ Actual field capacity, ha/h; and $\mathrm{TFC}=$ Theoretical field capacity, ha/h.

\section{Paddy seedlings planted per hill}

The number of paddy seedlings planted per hill (bunch of seedlings) was recorded from 
randomly selected hills, at four different locations in the field in each replication, by counting the number of seedlings at the individual hill. An average of all the readings was taken to calculate the number of paddy seedlings planted per hill.

\section{Seedling to seedling distance}

The seedling to seeding distance was recorded by measuring the distance between two seedlings selected randomly at four different locations in the field in each replication. A $300 \mathrm{~mm}$ scale will be used to measure the distance between the seedling. Seedling to seeding distance was calculated from an average of all the readings taken.

\section{Paddy hills planted}

A square quadrant $(1 \mathrm{~m} \times 1 \mathrm{~m})$ was used to record the number of paddy seedling planted in a square meter area (seedling density). The number of seedling, inside the area of square quadrant was counted from randomly selected four locations in the field in each replication. An average of all the readings was taken and number of paddy seedling in a square meter area was calculated.

\section{Missing seedling}

A seedling without seedlings was taken as missing seedling. A square quadrant (1 $\mathrm{m} \mathrm{x} 1$ m) was used to record the total number of seedling and missing hills in a square meter area. The observations were taken, inside the area of square quadrant, from randomly selected four different locations in the field in each replication. An average of all the readings of number of seedling missing was taken and number of missing seedling in a square meter area was calculated. The percentage of missing seedling was calculated by taking the ratio of total number missing seedling to the total number of paddy seedling planted in square meter area as expressed in following equation

Missing seedling, $\%=\frac{H m}{H t} \times 100$

where,

$\mathrm{Hm}=$ Number of missing seedling in the sampling area; and

$\mathrm{Ht}=$ Total number of seedling planted in the sampling area.

\section{Floating seedling}

Floating seedling are those seedling where all seedlings in a seedling are either floating on the surface or just placed on the surface of the mud. A square quadrant (1 $\mathrm{m} \mathrm{x} 1 \mathrm{~m}$ ) was used to record the number of floating seedling in a square meter area. The observations were taken from randomly selected four different locations in the field in each replication. Number of floating seedling in a square meter area was calculated from an average of all the readings. The Percentage of floating seedling was calculated by following equation

Floating seedling, $\%=\frac{H f}{H t} \times 100$

where,

Hf = Number of floating seedling in the sampling area; And

$\mathrm{Ht}=$ Total number of seedling in the sampling area.

\section{Buried seedling}

Seedling which are completely buried under the soil after the transplanting are called buried seedling. A square quadrant (1 $\mathrm{m} \mathrm{x} 1$ $\mathrm{m})$ was used to record the number of buried seedling in a square meter area. The observations were taken from randomly selected four different locations in the field in 
each replication. Number of buried seedling in a square meter area was calculated from an average of all the readings. The percentage of buried seedling was calculated by following equation:

Buried seedling, $\%=\frac{H b}{H t} \times 100 \quad \ldots$.

where,

$\mathrm{Hb}=$ Number of buried seedling in the sampling area; and

$\mathrm{Ht}=$ Total number of seedling in the sampling area.

\section{Planting efficiency}

It is the ratio of number of hills with seedlings (planted + floating + buried) to the total number of seedling expressed in percentage1. It was calculated by following equation:

Planting efficiency, $\%=\left[1-\frac{H m}{H t}\right] \times 100$.

where,

$\mathrm{Hm}=$ Number of missing seedling in the sampling area; and

$\mathrm{Ht}=$ Total number of seedling in the sampling area.

\section{Results and Discussion}

The experiment was conducted at FMPE farm field of VIAET. During the experiment row to row distance was maintained $25 \mathrm{~cm}$ and plant to plant distance was maintained by 18 $20 \mathrm{~cm}$ because actually the plant to plant distance maintained as per operators accuracy. Before transplanting the field is well prepared with puddling. Generally the machine is pull type so accuracy is maintainby pulling uniformity. The main effectiveness of machine mainly depends on two factors i.e. number of hills per square meter and no of missing hills. In this work, the different data are measured and mentioned.

Missing hill ranges from $0-4$, average missing hills 2.1. Number of plant per $\mathrm{m}^{2}$ ranges from 41 to 64 , average 51.8. Number of hills per $\mathrm{m}^{2}$ range from 22 to 32 , average 25.8 . Number of floating seedling ranges from 0 to 4 , average 1.3. Number of buried seedling ranges 0 to 2 , average 1.2 .

\section{Field performance evaluation}

After completion of the field test it was found that field efficiency of the transplanter is varies between 44 to $52 \%$. Field efficiency depends on the standing water. In this trial it was found that efficiency is better for standing water having $0.6 \mathrm{~cm}$ compared to 0.3 $\mathrm{cm}$.

\section{Cost analysis}

Depreciation cost 3.24/- hour. Repair and maintenance cost $10 \%$ of initial price, 360/ year. Labour cost, 320 /day, 40 / per hour (8 hour/day).

In conclusion, at transplanting time, there is acute shortage of labour wage and delay transplanting operated. Hence there is urgent need to have mechanization in rice production which is reduce a labour work and time consume. Manually operated paddy transplanter is a solution of marginal and small farmers. The newly developed manual transplanter was evaluated. Missing hill is comparatively low while using in the field and row-row distance is maintained by $25 \mathrm{~cm}$. No of hills with no of seedlings per square meter is also maintained properly and it varies between 45 -55 seedlings per square meter. Field efficiency for designed transplanter is $52 \%$ for standing water of $0.6 \mathrm{~cm}$ and $44.4 \%$ for standing water of $0.3 \mathrm{~cm}$. 


\section{References}

Kumbhar Satish, Khot Sangram, Mohite Suraj and Pandit S.V. (2017) "Design Analysis and Fabrication of Manual Rice Transplanter" Int. J. of Innovative Research in Science, Engineering and Technology, Vol 6, Issue 3.

Singh Pankaj Kumar, Srivastav Harischand, Bind Abhikekh Kumar, Kumar Chandan and Jain Rohit (2017) "Rice Transplanting Machine" Int. J. of
Engineering Research and Application Vol. 7, Issue 6, pp. 71-75.

Karthik A.V., Bhat Akshay S, VB. Mahesh Kumar, Karanam Praveen, Naik Shramit, Ganesh, Shet Vishank, Upadhyaya Prathviraj, Bn. Rajesh and Verma Ravi (2018) "Design and Fabrication of Hybrid Rice Seedling Transplanter" Int. J. of Computational Engineering Research, Vol.08, Issue 2.

\section{How to cite this article:}

Surendra Pal, Ashok Tripathi, Suryakanta Khandai and Ashish Kumar Kerketta. 2018. Performance Evaluation and Cost Economics of Developed Manual Paddy Transplanter. Int.J.Curr.Microbiol.App.Sci. 7(12): 2690-2694. doi: https://doi.org/10.20546/ijcmas.2018.712.305 